\title{
Mössbauer studies of iron doped poly(methyl methacrylate) before and after ion beam modification
}

\author{
D R S SOMAYAJULU, C N MURTHY ${ }^{\dagger}$, D K AWASTHI ${ }^{*}$ N V PATEL and M SARKAR \\ Physics Department, Faculty of Science, MS University of Baroda, Vadodara 390 002, India \\ ${ }^{\dagger}$ Applied Chemistry Department, Faculty of Technology and Engineering, MS University of Baroda, \\ Vadodara 390 001, India \\ ${ }^{\ddagger}$ Nuclear Science Centre, New Delhi 110 067, India
}

MS received 14 April 2000; revised 24 May 2001

\begin{abstract}
High-energy $\mathrm{MeV}$ ions from accelerators are known to produce drastic modifications in polymers. The typical effects include chain scissions, crosslinks, molecular emission and double bond formation. Poly(methyl methacrylate) was doped with $\mathrm{Fe}(\mathrm{III})$ and irradiated with $95 \mathrm{MeV} \mathrm{O}^{7+}$ ions. ${ }^{57} \mathrm{Fe}$-Mössbauer studies were done on the doped samples before and after irradiation. Before irradiation, no Mössbauer absorption was observed. The irradiated samples showed a good Mössbauer absorption, which seems to indicate that there is a significant interaction between the metal ion and the polymer matrix. Two possibilities exist at these doses $\left(\sim 22 \times 10^{12}\right.$ ions/cm): $\mathrm{Fe}(\mathrm{III})$ ions may be bridging the various polymer segments through crosslinking or amorphization of the sample leading to Fe-C bonding. Studies of FTIR, conductivity and glass transition temperatures on these samples support these observations.
\end{abstract}

Keywords. Ion beam modification; poly(methyl methacrylate); Mössbauer; metal doping.

\section{Introduction}

Extensive uses of polymers are because of their variety of physical properties including their electrical and thermal properties. These properties depend on their structural characteristics brought about by chemical methods. Apart from their traditional applications as lightweight and tough materials, polymers are being extensively investigated for their electrical properties and other emerging applications as non linear optical materials. The essentially insulating polymers are being modified with very specific applications in view. They include hyperconjugated systems like polyacetylenes, polypyrroles etc for electrical conduction and liquid crystalline polymers for NLO applications.

Apart from the chemical modification for specific applications, the physical and chemical effects of ionizing radiation on polymeric systems has been well studied and documented (Chapiro 1962; Ouano et al 1976). It is known that irradiation up to doses of $10^{12}$ ions $/ \mathrm{cm}$ have been used to modify polymers. The chemical changes brought about by radiations which underlie these physical modifications are limited to a few basic processes: gas evolution, crosslinking and degradation. The same chemical changes are more dramatic in polymers because of the macromolecular structure of these materials. The kind of

\footnotetext{
*Author for correspondence
}

changes, which predominate, depends on the polymer type and radiation dosage.

Similar changes are seen when high-energy ions from accelerators are used. The typical effects include chain scissions, crosslinks and molecular emission. However, unlike the $\gamma$-radiation, the high-energy ions, which could be any ion from the periodic table, introduces very typical properties in the polymer material. It has been reported that momentum transferring nuclear collisions are about 20 times more effective in forming crosslinks than electronic excitations or ionizations (Klaumuenzer et al 1996; Kodoh et al 1996). Nonlinear effects were achieved by ion irradiation of Li and N in PMMA and PVAC (Lissard and Gurusamy 1995). The ion-irradiated polymers exhibited improved oxidation resistance and increased electrical conductivity. Optical devices such as $\gamma$-branches, couplers and Mach-Zehnder interferometers were produced using ion irradiation (Ruck et al 1995). The present study is focused on the modification of Fe doped PMMA and investigate the effect of $\mathrm{O}^{7+}$ ion irradiation of the doped PMMA in terms of the glass transition and dielectric loss.

\section{Experimental}

\subsection{Sample preparation}

Commercial samples of PMMA of about $10^{5}$ molecular weight were used for doping. PMMA was first dried in an 
oven at $50^{\circ} \mathrm{C}$ to remove moisture. This was then dissolved in acetone solvent. Similarly the required quantity of $\mathrm{FeCl}_{3}$ (anhydrous) was dissolved in acetone solvent. The two solutions were mixed in a fixed proportion and stirred thoroughly for about an hour and poured into clean glass trough. The solvent was evaporated at room temperature $\left(27^{\circ} \mathrm{C}\right)$ to get thin films of the doped PMMA. Residual solvent was removed under vacuum to get coloured transparent films. The films were used for Mössbauer studies and irradiation.

\subsection{Mössbauer studies}

All Mössbauer spectra were recorded at room temperature using $\mathrm{Co}^{57}(\mathrm{Rh})$ source in the constant acceleration mode. The line width of the spectrometer was $0.27 \mathrm{~mm} / \mathrm{sec}$. Spectra were recorded before and after irradiation.

\subsection{Irradiation}

All samples were irradiated with $95 \mathrm{MeV} \mathrm{O}^{7+}$ beam from the pelletron of the Nuclear Science Centre (NSC), New Delhi. The samples were irradiated with different fluence rates and different doses $\left(\sim 22 \times 10^{12}\right.$ ions $)$.

\section{$2.4 \quad F T I R$}

Infrared spectra of the unirradiated and irradiated samples were taken in the disc form on a Bomem infrared spectrometer at ten scans. The stretching frequencies of the carbonyl group were noted and the results are given in table 1 .

\subsection{Glass transition temperature}

Glass transition temperatures of unirradiated and irradiated samples were taken on a Mettler DSC 20 at scan rates of $5^{\circ} \mathrm{C} / \mathrm{min}$.

\subsection{Dielectric measurements}

Dielectric measurements on $1 \mathrm{~cm}$ diameter discs were made on samples after irradiation. Measurements were made on Schlumberger SI 1260, impedance-gain phase analyser at different frequencies. The samples were coated with silver paint to give good contact between the samples and the capacitor cell.

\section{Results and discussion}

Mössbauer spectra were recorded for the samples before and after irradiation. Before irradiation no sample showed any Mössbauer absorption. However, after irradiation with $95 \mathrm{MeV} \mathrm{O}^{+7}$ ions at different fluences, samples containing 5\% Fe gave reasonably good Mössbauer absorption while the $1 \%$ sample did not show any Mössbauer fraction. The spectra were least square fitted. Best fitting of the spectra were obtained with a quadrupole doublet. The parameters obtained are listed in table 1 and the spectra shown in figure 1.

The uniform yellow colour of the doped samples (before irradiation) showed that the $\mathrm{Fe}$ ions were dispersed well in the samples. Since no Mössbauer absorption was observed for the samples before irradiation it is possible that $\mathrm{Fe}$ ions were either residing in the voids between the chains or got attached to the $-\mathrm{COOCH}_{3}$ group in the side chain without crosslinking. Even in the event of the latter possibility the recoil free fraction will be negligibly small.

The value of the quadrupole splitting (QS) and isomer shift (IS) for the irradiated samples showed that $\mathrm{Fe}$ is in the charge state $3+$ or more. However, the IS values indicate that $\mathrm{Fe}$ is in the high spin state. From the Mössbauer parameters QS and IS values of each of the spectra, it may be concluded that $\mathrm{Fe}$ ions are in a unique environment.

At the energy densities used in the present studies two possibilities exist: crosslinking after intense scissioning of the main chain of PMMA or amorphization of the samples. In either case resonant absorption by $\mathrm{Fe}$ ions is

Table 1. Mössbauer and IR parameters of doped PMMA after irradiation.

\begin{tabular}{lccccc}
\hline Sample & $\% \mathrm{Fe}$ & Dose $\left(\times 10^{12}\right)$ & Q.S. $(\mathrm{mm} / \mathrm{sec})$ & I.S. (wrt. nat. Fe) & $\mathrm{v}_{\mathrm{CO}}\left(\mathrm{cm}^{-1}\right)$ \\
\hline Fe-PMMA & 5 & - & - & - & 1680 \\
1 & 5 & 22.90 & $0.45 \pm 0.04$ & $0.54 \pm 0.04$ & 1644 \\
& & & & & 1730 \\
3 & 5 & 2.74 & $0.39 \pm 0.04$ & $0.41 \pm 0.04$ & - \\
4 & 5 & 1.34 & $0.63 \pm 0.07$ & $0.62 \pm 0.08$ & 1607 \\
& 5 & 9.36 & $0.63 \pm 0.06$ & $0.50 \pm 0.07$ & 1720 \\
5 & 3 & 10.18 & & & 1648 \\
\hline
\end{tabular}

*No observable signal 


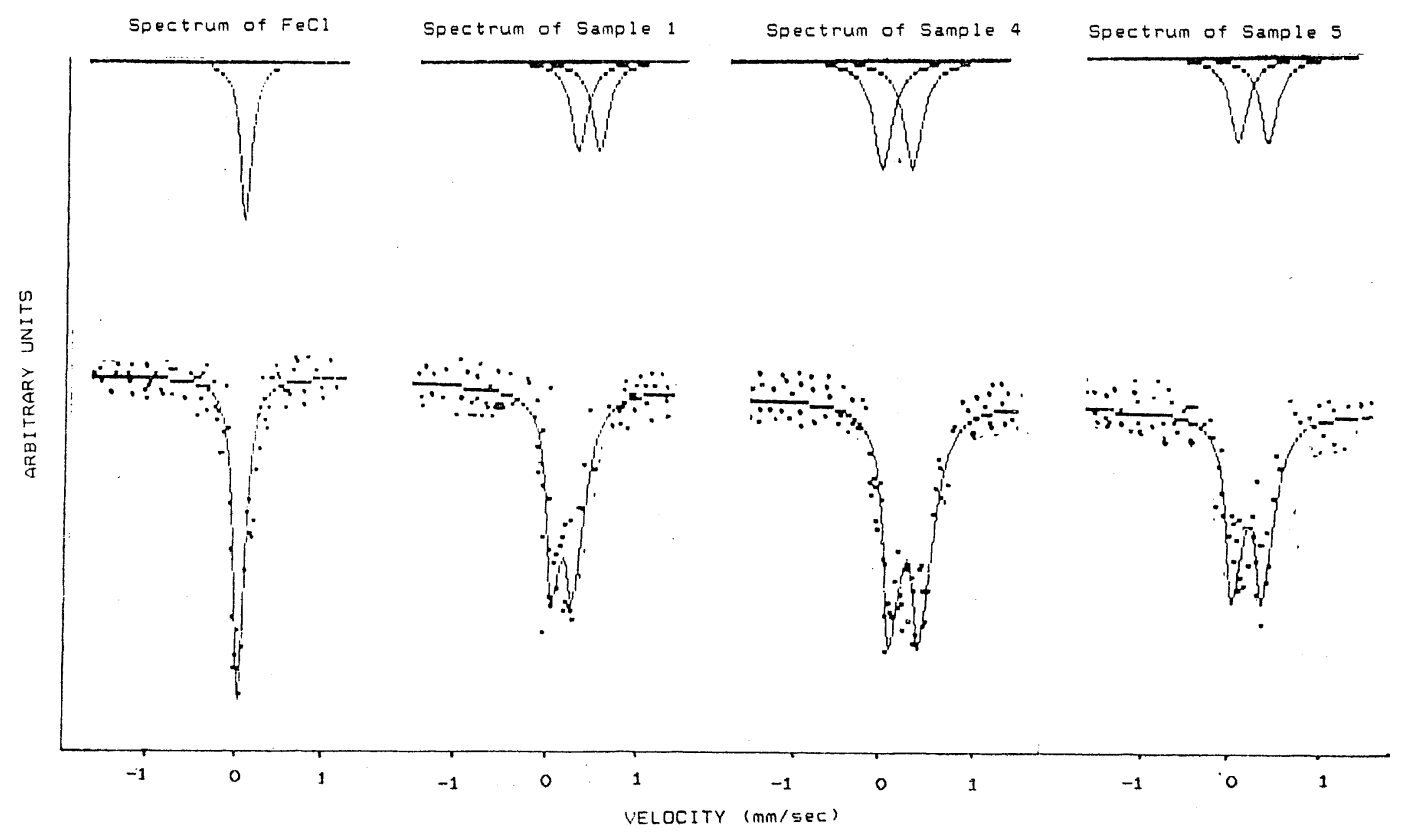

Figure 1. Mössbauer spectra of irradiated samples.

likely to take place. PMMA is known to undergo chain scissioning even at low (keV) ion energies. The high energy of the ion $(95 \mathrm{MeV})$ and hence energy per atom transferred to the polymer chains makes this scissioning more intense which may result in the amorphization of the sample. It is known that even in the case of the low energy projectiles and at large energy densities, hydrogenated amorphous carbon structures are formed. It is understandable since the range of the ions at the energies used is much larger than the thickness of the samples. Hence in the present case also it can be expected that there is a possibility of the formation of cluster of Fe with oxygen, hydrogen and carbon. However, the present study does not show any magnetic interaction and hence magnetic $\mathrm{Fe}-\mathrm{O}$ complexes can be ruled out. Also hydrogen depletion up to $85 \%$ is reported with ion irradiation. Hence $\mathrm{Fe}-\mathrm{C}$ interaction is more possible than $\mathrm{Fe}-\mathrm{H}$ or $\mathrm{Fe}-\mathrm{O}$. This is also confirmed by the single quadrupole doublet observed and it can be assumed that clusters of $\mathrm{Fe}-\mathrm{C}$ complex might be giving rise to the observed Mössbauer absorption.

Thus Mössbauer spectra gives an indication of the absence of any $\mathrm{Fe}-\mathrm{O}$ formation and the existence of $\mathrm{Fe}-\mathrm{C}$ interaction. To further analyse this the IR spectra of the doped samples were recorded before and after irradiation. The vibration frequencies of the $\mathrm{C}=\mathrm{O}$ bond are given in table 2. The unirradiated sample shows a $\mathrm{C}=\mathrm{O}$ stretching frequency at $1680 \mathrm{~cm}^{-1}$. Carbonyl compounds or esters show strong absorptions in the range $1600-1800 \mathrm{~cm}^{-1}$ depending on the immediate environment of the $\mathrm{C}=\mathrm{O}$. However, after irradiation, the single stretching frequency is seen to split to give two sharp frequencies one going on the lower side and the other to the higher side of $1680 \mathrm{~cm}^{-1}$. This indicates the presence of $\mathrm{Fe}-\mathrm{C}$ bonding leading to
Table 2. Peak transition temperatures of doped PMMA after irradiation.

\begin{tabular}{lcccc}
\hline Sample & $\begin{array}{c}\text { Dose } \\
\left(\times 10^{12} \text { ions }\right)\end{array}$ & $\% \mathrm{Fe}$ & $\begin{array}{c}\mathrm{T} \\
\left({ }^{\circ} \mathrm{C}\right)\end{array}$ & $\begin{array}{c}\Delta H \\
(\mathrm{~J} / \mathrm{G})\end{array}$ \\
\hline 1 & 22.90 & $5 \cdot 0$ & 168.4 & 2.78 \\
2 & 9.36 & 5.0 & 63.0 & 0.23 \\
\hline
\end{tabular}

the shift of the $\mathrm{C}=\mathrm{O}$ frequency to the lower frequency. The shift to the lower frequency is much more than the shift to the higher frequency. This effect at lower dosage compliments the QS and IS values obtained from Mössbauer. The $\mathrm{C}=\mathrm{O}$ stretching frequency has shifted to $1670 \mathrm{~cm}^{-1}$ whereas QS and IS values are higher at lower dosage of the irradiation. This shows that the $\mathrm{Fe}$ in the ionic form is in an unique environment and at lower dosage the $\mathrm{Fe}-\mathrm{C}$ interaction is much stronger than at higher dosage which tends to induce drastic changes in the microstructure.

The differential scanning calorimeter scans of the irradiated polymers with $5 \% \mathrm{Fe}$ at different dosages were carried out and the peak temperatures and the $\Delta H$ values are shown in table 2 . The results support the observation made previously. At higher fluences the amorphization is more than when the fluence is less. The peak temperature falls from $168 \cdot 4^{\circ} \mathrm{C}$ for sample 1 to $63^{\circ} \mathrm{C}$ for sample 4 . Both samples 1 and 4 contain $5 \%$ Fe but sample 1 was irradiated with a higher dose than sample 4. This difference in the dosages is also reflected in the $\Delta H$ values, which falls from $2.78 \mathrm{~J} / \mathrm{G}$ to $0.23 \mathrm{~J} / \mathrm{G}$. The increased amorphization due to the higher dosage of irradiation results in the increased peak temperature. 


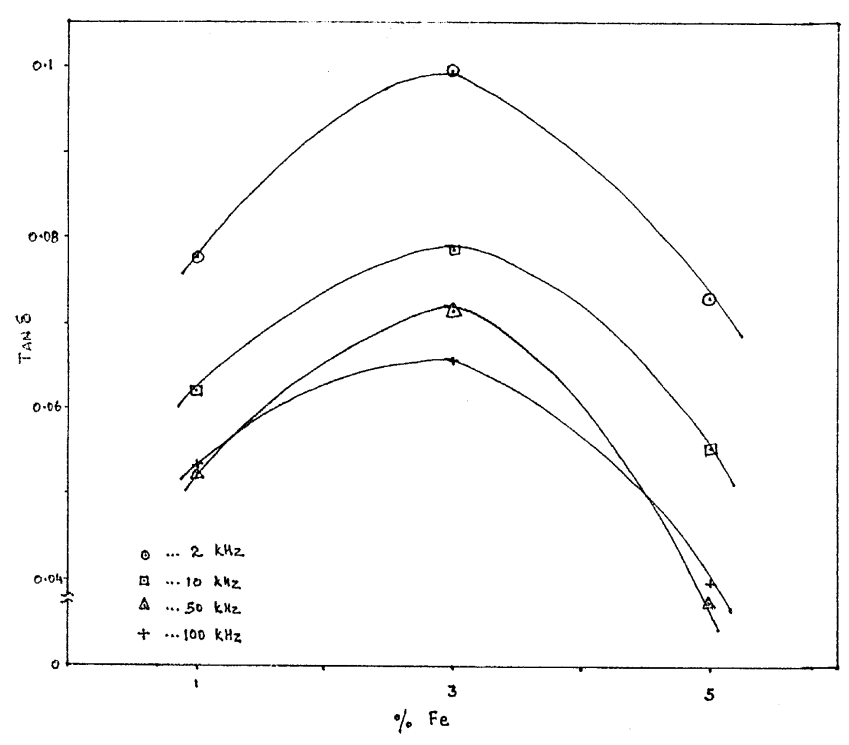

Figure 2. Variation of $\tan \delta$ with $\% \mathrm{Fe}$.

All the irradiated polymers were tested for their dielectric strengths at different frequencies. The $\tan \delta$ values versus the $\% \mathrm{Fe}$ plot is shown in figure 2 . The results reported for $5 \% \mathrm{Fe}$ are for the sample with lower dosage $\left(9.39 \times 10^{12}\right.$ ions/cm $)$ as the higher dosage sample was highly brittle for coating with silver paint and could not be handled. In all the cases the loss for $5 \%$ sample was much lower than for the $1 \%$ or the $3 \%$ samples after irradiation. The frequency dependence of the loss follows the expected reduction from 0.07 to 0.40 when the frequency changes from $2 \mathrm{kHz}$ to $100 \mathrm{kHz}$. The pure PMMA has a loss factor of $0 \cdot 19$ at 60 cycles and 0.08 at 10 cycles. The effect of still lower dosages would give a better insight into the variation of the loss factors.

\section{Conclusions}

The formation of $\mathrm{Fe}-\mathrm{C}$ clusters and the $\mathrm{Fe}$ ions acting as crosslinks between the polymer chains have been observed by Mössbauer spectra. The ion beam passes through; the sample after disturbing the polymer chains and inducing chain scission. In the present study the beam ion passes through; which is reflected in the Mössbauer spectra (no magnetic interaction). Further studies with low energy projectiles, different ion dose and also different ions may give more insight into this mechanism of $\mathrm{Fe}$ complex formation or crosslinking of chains via the $\mathrm{Fe}$ ions in this polymer sample.

\section{References}

Chapiro A 1962 Radiation chemistry of polymeric systems (New York: Inter Science John Wiley \& Sons)

Klaumuenzer S, Zhn Q Q, Schnabel W and Shumacher G 1996 Nucl. Instrum. Meth. Phys. Res. B116 154

Kodoh H, Sasuga T, Seguchi T and Katsumura Y 1996 Polymer 372903

Lissard R A and Gurusamy M 1995 Nucl. Instrum. Meth. Phys. Res. B105 220

Ouano A C, Johnson D E, Dawson B and Pederson L A 1976 J. Polym. Sci. Polym. Chem. Ed. 14701

Ruck D M, Brunner S, Tinschert K and Frank W F 1995 Nucl. Instrum. Meth. Phys. Res. B106 447 